\title{
Biochemical indices and neuromuscular function tests in rural Gambian schoolchildren given a riboflavin, or multivitamin plus iron, supplement
}

\author{
BY C. J. BATES ${ }^{1}$, P. H. EVANS ${ }^{1}$, G. ALLISON ${ }^{1 *}$, B. J. SONKO ${ }^{1}$, S. HOARE ${ }^{1} \dagger$, \\ S. GOODRICH ${ }^{2}$ AND T. ASPRAY ${ }^{1}$ \\ ${ }^{1}$ Medical Research Council, Dunn Nutrition Unit, Milton Road, Cambridge CB4 IXJ and Keneba, \\ The Gambia \\ ${ }^{2}$ Applied Psychology Unit, 15 Chaucer Road, Cambridge CB2 2EF
}

(Received 19 October 1993 - Revised 17 December 1993 - Accepted 14 January 1994)

\begin{abstract}
Ninety preselected children, aged between 8 and 14 years, living in two rural West African (Gambian) villages, were randomly divided into three groups, matched for age and sex. One group received a placebo (lactose) tablet, one received ribofiavin $(5 \mathrm{mg})$ on $5 \mathrm{~d}$ every week, which was sufficient to correct an endemic riboflavin deficiency, and one received a multivitamin supplement (Protovit; Hoffmann La Roche), on $5 \mathrm{~d}$ every week, together with $\mathrm{FeSO}_{4}(200 \mathrm{mg})$ once weekly, and the supplements were given for 1 year. Neuromuscular tests, including arm tremor and manipulative skills, were performed on three occasions: once just before the introduction of the supplements; again 6 weeks after commencing the supplements; and again 1 year later. Venous blood samples were collected at the same time as the first two sets of neuromuscular tests. These samples were used for haematology and nutrient status indices: plasma ferritin, ascorbic acid, cyanocobalamin and pyridoxal phosphate, and erythrocyte tests for folate status, for riboflavin status (erythrocyte glutathione reductase activation coefficient) and thiamine status (erythrocyte transketolase activation coefficient). The riboflavin in both supplements achieved a clear-cut response in biochemical status, which was dose-dependent. The pyridoxine, ascorbic acid and Fe components of the multivitamin also affected the associated biochemical indices. Although overall the arm tremor and related neuromuscular function tests did not respond significantly to the supplements, significant improvement was seen in the boys for the arm-tremor test in both the supplemented groups.
\end{abstract}

Vitamin supplement: Third World children: Neuromuscular tests

Exploration of physiological benefits arising from correction of endemic nutrient deficiencies by nutrient supplementation in under-privileged human communities is essential for the development of nutritional knowledge. Controlled supplementation studies can yield reliable evidence about the effects of nutrient deficiencies, and the consequences of their correction. Studies exploring the functional effects of micronutrient deficiencies and their correction have been undertaken by us over an extended period, in high-risk subgroups of a rural West African (Gambian) population (Bates et al. 1982 b, 1989; Powers \& Bates, 1987; Bates \& Powers, 1989). Of potential relevance for the search for functional indices of marginal micronutrient deficiencies, some interesting neuromuscular effects were reported during supplementation studies of rural Indian schoolchildren (Bamji et al. 1979, 1982; Prasad et al. 1990). These effects were associated with the correction of endemic B-vitamin deficiencies, and especially that of riboflavin, and were therefore potentially relevant to West African communities.

* Present address: Auchlunies, Blairs, Aberdeen, AB1 5YS.

$\uparrow$ Present address: 41 Long Meadow, Darras Hall, Ponteland, Northumberland NE20 9DX. 
Riboflavin deficiency is universally present and is frequently severe in rural Gambian subjects, including schoolchildren (Powers et al. 1983, 1985, 1987; Bates \& Powers, 1989; Bates et al, 1989). It may affect Fe status (Powers \& Bates, 1987) by impairing Fe absorption, mobilization, and mechanisms which minimize the loss of Fe through mucosal cell turnover (Powers et al. 1993). Other micronutrients which may also be deficient include retinol (Nathanail \& Powers, 1992); ascorbic acid (Prentice et al. 1983); folate (Fuller et al. 1988); Zn (Bates et al. 1993), and perhaps others not yet studied. Seasonal fluctuations affect both nutrient intakes and status indices (Bates \& Powers, 1989), and one typical pattern is of relatively good status in the later part of the dry season, followed by a rapid deterioration during the rainy season.

Evidence is also available from other studies (Sterner \& Price, 1973; Haralambie, 1976) suggesting that the dietary riboflavin supply of human subjects might affect neuromuscular function. Benton (1992) has discussed ways in which micronutrient supplements might affect neurological performance, including effects on attention-span.

The present study used a preselection procedure to ensure that the study group would comprise children with relatively poor neuromuscular co-ordination at the outset. Tests to explore several different aspects of neuromuscular co-ordination, and of manipulative skills, were selected. In addition to riboflavin, a multinutrient supplement was tested, since the different micronutrients have different roles in neural and in neuromuscular physiology. The total duration of the intervention was 1 year, to match that of the Indian studies (Bamji et al. 1982; Prasad et al. 1990). Biochemical and haematological status indices were measured, both before supplementation (to verify the presence of deficient status near the outset), and at 6 weeks after the start of supplementation (to check the extent of biochemical improvement in groups receiving the supplements). Anthropometric measurements (height, weight and mid-upper-arm circumference (MUAC)) were made after 6 weeks and 1 year of supplementation.

Part of this work has been reported as an abstract (Bates et al. 1993).

\section{SUBJECTS AND METHODS}

A total of 247 subjects, aged between 8 and 14 years and living in the rural villages of Keneba and Kanton Kundar in The Gambia, were included in the pre-selection trial. They included all the eligible children in this age range from the two villages during October 1991. They were divided into 1 year age-bands, and each child was asked to maintain a narrow cylindrical metal probe in the centre of a hole $(5 \mathrm{~mm}$ diameter) in a metal sheet (Test No. 1) as described by Prasad et al. 1990). They sat on a chair in front of the device, elbows resting on a table, under standardized conditions. Following a single practice run the numbers of accidental contacts during two (1-min) test periods were recorded by an electronic counter.

When all these results were subdivided by age, it was found that for the 8-9-year-old group $17 \%$ were in the lowest, $31 \%$ in the middle and $52 \%$ in the highest tertile; for the $10-12$-year-old group, $30 \%$ were in the lowest, $32 \%$ in the middle and $38 \%$ in the highest tertile, and for the 13-14-year-old group, $48 \%$ were in the lowest, $35 \%$ in the middle and $17 \%$ in the highest tertile. Thus the performance in the test clearly is age-dependent, and it was therefore important to stratify the intervention groups by age.

From each 1-year age-band, fifteen subjects with the poorest performance (highest contact scores) were then selected for inclusion in the main trial. Subsequent neuromuscular tests on these selected subjects were of four types, which required a total of about $15 \mathrm{~min}$ testing for each subject. All tests were done in duplicate. Test No. 1 was as described above, but with two hole sizes used successively (respectively (a) $3 \mathrm{~mm}$ and (b) $5 \mathrm{~mm}$ in diameter). In test No. 2 a ring $(15 \mathrm{~mm}$ diameter) was moved along the path of a contorted wire; 
accidental contacts were recorded electronically. In test No. 3 a hand-held probe was moved as rapidly as possible between each of two $40 \mathrm{~mm}^{2}$ 'targets', $356 \mathrm{~mm}$ apart, the number of 'hits' being recorded during a 1-min period. In test no. 4 during a 4-min timeinterval as many as possible of a set of blunt cylindrical metal 'pins' $1.6 \mathrm{~mm}$ in diameter were transferred, with the aid of forceps, from a tray into a matrix of similar-sized holes drilled in a peg-board (Anastasi, 1976).

Tests 1 and 2 were intended as indicators of hand 'tremor' (neuromuscular control), whereas tests 3 and 4 were intended as indicators of speed and dexterity. Each child was instructed to use his (or her) 'dominant' hand only, and each was initially given standardized individual instruction and demonstration by the same invigilator (fieldworker). Each child was permitted one practice run before the definitive test. The tests were performed in the village environment to avoid possible adverse psychological effects of an unfamiliar location. They were performed initially during mid-October 1991, soon after the end of the rainy season, again in early December 1991, after 6 weeks of supplementation, and finally in October 1992, 1 year after the start of the study.

The preselected subjects were stratified by age and sex, and were then randomly assigned to each of three supplement groups (twenty-nine to thirty-one subjects per group). Members of group 1 (the placebo group) received one (colour-matched) tablet of lactose on $5 \mathrm{~d}$ each week, members of group 2 (the riboflavin group) received one tablet containing riboflavin $(5 \mathrm{mg})$ in a lactose base on $5 \mathrm{~d}$ each week, and members of group 3 , the multinutrient group, received one tablet of 'Protovit' (Hoffmann-la-Roche, Basle, Switzerland) on $5 \mathrm{~d}$ each week, plus one tablet of $\mathrm{FeSO}_{4}(200 \mathrm{mg})$ once weekly. Each 'Protovit' tablet contained: retinol $450 \mu \mathrm{g}$; cholecalciferol $6 \mu \mathrm{g}$; $\alpha$-tocopherol $10 \mathrm{mg}$; ascorbic acid $40 \mathrm{mg}$; thiamin $1 \mathrm{mg}$; riboflavin $1 \mathrm{mg}$; pyridoxine $1.5 \mathrm{mg}$; nicotinamide $10 \mathrm{mg}$; pteroylmonoglutamic acid $150 \mu \mathrm{g}$; cyanocobalamin $4 \mu \mathrm{g}$; biotin $100 \mu \mathrm{g}$ and calcium pantothenate $5 \mathrm{mg}$. The supplements were given for 1 year and records of compliance were maintained. Neither the subjects nor the observers who performed the physiological tests had access to the supplement code.

At two time-points (time-point 0 just before starting the supplement, and a second timepoint 6 weeks later) a $5 \mathrm{ml}$ venous blood sample was taken from the antecubital vein of each subject, for haematological (EDTA sub-sample) and biochemical (heparinized sub-sample) indices. The Coulter-based haematological measurements, performed within a short time of collection, included an erythrocyte count, mean erythrocyte volume, packed cell volume, total leucocyte count, and haemoglobin concentration. Biochemical analyses were performed on samples initially stabilized in Keneba, then frozen at $-40^{\circ}$ and transported to Cambridge on dry ice. These analyses comprised: plasma ascorbic acid in metaphosphoric acid-stabilized plasma samples (Vuilleumier \& Keck, 1989); plasma pyridoxal phosphate (tyrosine decarboxylase apoenzyme reactivation procedure, modified from ShinBuehring et al. 1981 and Camp et al. 1983); erythrocyte folate in ascorbate-stabilized whole-blood samples using the Quantaphase -1 folate assay kit and procedure of BioRad Laboratories (Hercules, CA, USA); plasma cobalamins using the Quantaphase B $_{12}$ assay kit from the same manufacturer; plasma ferritin by an ELISA assay (Anderson \& Kelly, 1981); the erythrocyte glutathione reductase activation coefficient (EGRAC) assay for riboflavin status (Powers et al. 1983); and the erythrocyte transketolase (ETKAC) assay for thiamin status (Vuilleumier et al. 1990).

Statistical analyses of intergroup comparisons employed one-way ANOVA tests, followed by the Scheffé or Student's $t$ test, to compare group means, and in certain cases this was confirmed by multiple regression, using the post-supplement index value as the independent variable, and the pre-supplement value, plus supplement type (assigned 0 for placebo group; 1 for supplemented group) as dependent variables. 
The study was approved by the Medical Research Council Gambian ethics committee.

\section{RESULTS}

Table 1 gives the starting values, before supplementation, of the biochemical and physiological indices which were included in the study. The three groups were well-matched with each other following the randomization procedure. Many of the biochemical index values were in the deficient range, by comparison with published norms for Western populations, as indicated by the following percentages of values outside normal ranges (Machlin, 1984): plasma ascorbate, $35 \%$ of values were below $11 \mu \mathrm{M}(0.2 \mathrm{mg} / \mathrm{dl})$; EGRAC, $97 \%$ of values were above 1.4 ; ETKAC, $8 \%$ of values were above 1.25 ; erythrocyte folate, $4 \%$ of values were below $360 \mathrm{nM}(160 \mathrm{ng} / \mathrm{ml})$.

As expected, riboflavin status values were almost entirely in the deficient range. Plasma ascorbate was partly in the deficient range, consistent with the fact that the samples were obtained at the end of the rainy season, when ascorbic acid-rich foods have been virtually absent from the Gambian diet for several months (Bates et al. 1982a). Plasma pyridoxal phosphate values were also generally at the lower end of the expected range, but the indices of thiamin and folate status appeared generally to be within normal or intermediate ranges. Since the second blood sample was taken only 6 weeks after the first, it was not surprising that the placebo group generally exhibited only moderate (seasonally-related) changes in status indices (Table 2). However, the additional nutrient supplements given to groups 2 and 3 clearly did affect some of the status indices: thus riboflavin status clearly improved in both groups 2 and 3, with the most clear-cut response in group 2, as expected. This improvement did not differ significantly between the sexes. Ascorbic acid and vitamin $\mathbf{B}_{6}$ status improved in group 3 but not in group 2, consistent with these nutrients in the multivitamin given to group 3 . Thiamin status exhibited a modest improvement, marginally significant $(P<0.05)$ if group 2 or groups 1 and 2 combined are compared by Student's $t$ test with group 3. Erythrocyte folate and plasma cobalamins were not significantly responsive to the multivitamin supplement which contained these vitamins, although the differences for folate were in the expected direction.

Haematological status indices exhibited a moderate proportion of values below the accepted cut-off of normality (Dacie \& Lewis, 1975) in the pre-supplement samples: blood haemoglobin, $18 \%$ of values were below $115 \mathrm{~g} / 1$; mean cell volume, $8 \%$ of values were below $77 \mathrm{fl}$. None of the haematology indices were significantly affected by either the riboflavin or the multivitamin plus Fe supplement at the 6-week time interval (Table 3 ). The plasma ferritin difference was, however, in the direction consistent with a possible $\mathrm{Fe}$ supplement effect in group 3 ; the overall mean ferritin concentration was $36.3 \mathrm{ng} / \mathrm{ml}$ (range $0 \cdot 2-423 \mathrm{ng} / \mathrm{ml}$, median $19 \cdot 1 \mathrm{ng} / \mathrm{ml}$ ).

The anthropometric indices also exhibited a moderate proportion of values outside the normal limits at the start of the study: body weight $13.8 \%$ below, and height $8 \%$ below the 2.5 percentile of the age-adjusted norms (Tanner et al. 1966). None of the anthropometric index changes (bodyweight, height, MUAC) were significantly affected by the riboflavin or the multivitamin plus Fe supplements at 1 year following their introduction (Table 3).

The neuromuscular function and manipulation-efficiency indices exhibited a moderate overall improvement (reduction in index values $1(\mathrm{a}), 1(\mathrm{~b})$ and 2 ; increase in index values 3 and 4) in all three supplement groups after 1 year (Table 4). These increases may have been age- or test-familiarity-related. Overall, there were no significant inter-group differences in the changes between time-point 0 and 6 weeks or between time point 0 and 1 year. However, when the responses were subdivided between the sexes, the tremor test with the probe revealed a significant difference in the direction of benefit (i.e. fewer 
Table 1. Baseline characteristics of three test-groups of Gambian schoolchildren, aged 8-14 years, before supplementation with lactose (placebo), riboflavin, or a multinutrient supplement

(Mean values with their standard errors for $n$ subjects)

\begin{tabular}{|c|c|c|c|c|c|c|}
\hline & \multicolumn{2}{|c|}{$\begin{array}{c}\text { Group 1: } \\
\text { placebo }(n 31)\end{array}$} & \multicolumn{2}{|c|}{$\begin{array}{l}\text { Group 2: } \\
\text { riboflavin }(n 30)\end{array}$} & \multicolumn{2}{|c|}{$\begin{array}{c}\text { Group 3: } \\
\text { multinutrient }(n \text { 29) }\end{array}$} \\
\hline & Mean & $\mathbf{S E}$ & Mean & $\mathbf{S E}$ & Mean & SE \\
\hline $\begin{array}{l}\text { Age (years) } \\
\% \text { Male }\end{array}$ & $\begin{array}{l}11 \cdot 1 \\
47\end{array}$ & $0 \cdot 32$ & $\begin{array}{l}11 \cdot 1 \\
39\end{array}$ & $0 \cdot 30$ & $\begin{array}{l}11 \cdot 2 \\
36\end{array}$ & 0.32 \\
\hline Body weight $(\mathrm{kg})^{*}$ & $28 \cdot 2$ & 1.25 & 28.8 & $0-97$ & $29 \cdot 9$ & 1.37 \\
\hline Height $(\mathrm{m})^{*}$ & $1 \cdot 364$ & 0.0188 & 1.373 & 0.0162 & 1.389 & 0.0181 \\
\hline $\begin{array}{l}\text { Mid-upper-arm } \\
\text { circumference (mm)* }\end{array}$ & 174 & $4 \cdot 1$ & 175 & $3 \cdot 1$ & 175 & $4 \cdot 3$ \\
\hline \multicolumn{7}{|l|}{ Biochemical indices } \\
\hline Plasma ascorbate $(\mu \mathrm{mol} / \mathrm{l})$ & $21 \cdot 8$ & $3 \cdot 0$ & $17 \cdot 1$ & $3 \cdot 0$ & 21.9 & $3 \cdot 2$ \\
\hline $\begin{array}{l}\text { Plasma cobalamins } \\
(\mathrm{pmol} / \mathrm{l})\end{array}$ & 738 & 75 & 617 & 78 & 663 & 80 \\
\hline $\begin{array}{l}\text { Plasma pyridoxal } \\
\text { phosphate }(\mathrm{nmol} / \mathrm{l})\end{array}$ & $12 \cdot 4$ & $1 \cdot 17$ & $13 \cdot 7$ & $1 \cdot 13$ & $13 \cdot 5$ & $1 \cdot 22$ \\
\hline EGRAC $\dagger$ & 1.97 & 0.05 & 1.95 & 0.06 & $2 \cdot 00$ & 0.07 \\
\hline ETKAC $\ddagger$ & $1 \cdot 18$ & 0.011 & $1 \cdot 18$ & 0.011 & $\mathrm{l} \cdot 18$ & 0.011 \\
\hline Erythrocyte folate $(\mathrm{nmol} / \mathrm{l})$ & 637 & 30 & 600 & 32 & 603 & 32 \\
\hline \multicolumn{7}{|l|}{ Haematology } \\
\hline Erythrocytes $\times 10^{-6} / \mu l$ & $39 \cdot 05$ & 0.93 & 38.74 & 0.70 & $39 \cdot 20$ & 0.50 \\
\hline Mean cell volume (fl) & $83 \cdot 1$ & 1.00 & $85 \cdot 6$ & $0 \cdot 73$ & $85 \cdot 2$ & 0.92 \\
\hline Packed cell volume & 0.334 & 0.0075 & $0 \cdot 343$ & 0.0065 & 0.348 & 0.0053 \\
\hline Leucocytes $\times 10^{-3} / \mu 1$ & 6.72 & 0.31 & 7.09 & 0.44 & $7 \cdot 21$ & 0.29 \\
\hline Haemoglobin $(\mathrm{g} / \mathrm{l})$ & $117 \cdot 5$ & 2.6 & 121.0 & $2 \cdot 1$ & $122 \cdot 6$ & 1.9 \\
\hline \multicolumn{7}{|l|}{ Neuromuscular score§ } \\
\hline Test 1(a) (small hole) & 136 & 13 & 136 & 13 & 128 & 12 \\
\hline Test 1 (b) (larger hole) & 56 & 7 & 59 & 7 & 66 & 8 \\
\hline Test 2 (ring) & $26 \mathrm{I}$ & 21 & 254 & 17 & 252 & 19 \\
\hline Test 3 (probe) & $43 \cdot 8$ & $1 \cdot 4$ & $44 \cdot 1$ & 1.8 & $43 \cdot 0$ & 1.6 \\
\hline Test 4 (pins) & 20.8 & 0.9 & $20 \cdot 4$ & 1.5 & $19 \cdot 3$ & $1 \cdot 2$ \\
\hline
\end{tabular}

* At the 6-weeks time-point. Other measurements were made just before the start of supplementation.

$\uparrow$ Erythrocyte glutathione reductase activation coefficient.

\$ Erythrocyte transketolase activation coefficient.

$\S$ For a detailed description of the test procedures, see pp. 602-603.

contacts) in each of the two supplemented groups, compared with the placebo group. This was demonstrated by one-way ANOVA followed by Scheffé test, and also by multiple regression (Table 5). It was somewhat stronger when the older boys ( $>11$ years) were selected from the entire data set (Table 5). The boys, but not the girls, also exhibited a direct linear correlation between the change in riboflavin index (EGRAC) values and the change in tremor (probe) test result between time-point 0 and 6 weeks $(P=0.07$ to 0.09$)$, which is consistent with the prediction that an improved riboflavin status (lower EGRAC) was correlated with reduced tremor (fewer contacts). Another supplement-related change which was significant in the boys, but not the girls, was test no. 4 at 1 year. Here the multinutrientsupplemented group 3 exhibited the greatest increase, which was significant $(P<0.05)$ by ANOVA followed by Student's $t$ test in comparison with either of groups 1 or 2 (Table 5 ). 
Table 2. Biochemical changes in the blood of Gambian schoolchildren, aged 8-14 years, following supplementation with lactose (placebo), riboflavin, or a multinutrient supplement for 6 weeks*

(Mean values and their standard errors, with the number of subjects indicated in parentheses)

\begin{tabular}{|c|c|c|c|c|c|c|}
\hline & \multicolumn{2}{|c|}{$\begin{array}{l}\text { Group 1: } \\
\text { placebo }\end{array}$} & \multicolumn{2}{|c|}{$\begin{array}{l}\text { Group 2: } \\
\text { riboflavin }\end{array}$} & \multicolumn{2}{|c|}{$\begin{array}{l}\text { Group 3: } \\
\text { multinutrient }\end{array}$} \\
\hline & Mean & $\operatorname{sE}(n)$ & Mean & $\operatorname{SE}(n)$ & Mean & $\operatorname{SE}(n)$ \\
\hline Plasma ascorbate $(\mu \mathrm{mol} / 1)$ & $-5 \cdot 60^{\mathrm{a}}$ & $4 \cdot 32(29)$ & $+0.80^{4}$ & $2 \cdot 00(29)$ & $+18 \cdot 10^{\mathrm{b}}$ & $5 \cdot 34(28)$ \\
\hline $\begin{array}{l}\text { Plasma cobalamins } \\
(\mathrm{pmol} / \mathrm{l})\end{array}$ & $-181^{a}$ & $55(25)$ & $-41^{\mathrm{a}}$ & $59(22)$ & $-94^{\mathrm{a}}$ & $57(23)$ \\
\hline $\begin{array}{l}\text { Plasma pyridoxal phosphate } \\
\text { (nmol/1) }\end{array}$ & $+2 \cdot 45^{a}$ & $1.93(27)$ & $+2.82^{\mathfrak{a}}$ & $1.86(29)$ & $+17.09^{b}$ & $2 \cdot 00(25)$ \\
\hline $\operatorname{EGRAC}^{+}$ & $-0.04^{a}$ & $0.04(31)$ & $-0.71^{b}$ & $0.05(28)$ & $-0 \cdot 46^{\mathrm{c}}$ & $0 \cdot 05(28)$ \\
\hline ETKAC $\dagger$ & $+0.012^{a}$ & $0.017(29)$ & $+0.020^{\mathrm{a}}$ & $0.017(30)$ & $-0.047^{\mathrm{a}}$ & $0.017(28)$ \\
\hline Erythrocyte folate $(\mathrm{nmol} / \mathrm{l})$ & $+101^{\mathrm{a}}$ & $68(31)$ & $+150^{2}$ & $72(28)$ & $+216^{\mathrm{a}}$ & $73(27)$ \\
\hline
\end{tabular}

EGRAC, erythrocyte glutathione reductase activation coefficient; ETKAC, erythrocyte transketolase activation coefficient.

$a, b, c$ Mean values within each index bearing different superscript letters were significantly different $(P<0 \cdot 01)$ by one-way ANOVA followed by the Scheffé test.

* For details of subjects and procedures, see pp. 602-604.

$\dagger$ For EGRAC and ETKAC, an improvement in status is indicated by a negative value for the change, whereas for the other three indices an improvement is indicated by a positive change and a deterioration by a negative change.

Table 3. Changes in haematological and anthropometric variables in Gambian schoolchildren, aged 8-14 years, following supplementation with lactose (placebo), riboflavin, or a multinutrient supplement for 6 weeks or 1 year*

(Mean values and their standard errors, with the number of subjects indicated in parentheses. Group means represent the mean of individual changes, for each test as specified)

\begin{tabular}{|c|c|c|c|c|c|c|}
\hline & \multicolumn{2}{|c|}{$\begin{array}{l}\text { Group 1: } \\
\text { placebo }\end{array}$} & \multicolumn{2}{|c|}{$\begin{array}{l}\text { Group 2: } \\
\text { riboflavin }\end{array}$} & \multicolumn{2}{|c|}{$\begin{array}{l}\text { Group 3: } \\
\text { multinutrient }\end{array}$} \\
\hline & Mean & SE $(n)$ & Mean & SE $(n)$ & Mean & SE $(n)$ \\
\hline \multicolumn{7}{|c|}{ After 6 weeks' supplementation } \\
\hline Erythrocytes $\times 10^{-6} / \mu 1$ & $+2 \cdot 24$ & $1.01(21)$ & $+1 \cdot 31$ & $0.97(26)$ & +1.87 & $0.67(24)$ \\
\hline Mean cell volume (f) & $-2 \cdot 61$ & $0.82(23)$ & -1.07 & $0.46(28)$ & -1.65 & $0.54(26)$ \\
\hline Packed cell volume $(\%)$ & $+1 \cdot 4$ & $1 \cdot 1(21)$ & +0.8 & $0.96(26)$ & +0.6 & $0.6(24)$ \\
\hline Leucocytes $\times 10^{-3} / \mu 1$ & +0.69 & $0.28(20)$ & +0.97 & $0 \cdot 41(26)$ & $+1 \cdot 28$ & $0 \cdot 23(24)$ \\
\hline Haemoglobin $(g / 1)$ & $+4 \cdot 9$ & $2 \cdot 5(22)$ & $+4 \cdot 6$ & $3 \cdot 0(25)$ & $+3 \cdot 5$ & $1.8(24)$ \\
\hline \multicolumn{7}{|c|}{ After 1 years' supplementation } \\
\hline Body weight $(\mathrm{kg})$ & +2.06 & $0 \cdot 31(30)$ & $+1 \cdot 81$ & $0.31(29)$ & +1.69 & $0 \cdot 33(27)$ \\
\hline Height $(\mathrm{m})$ & $+0 \cdot 034$ & $0.0083(30)$ & +0.044 & $0.0083(30)$ & +0.042 & $0.0087(27)$ \\
\hline $\begin{array}{l}\text { Mid-upper-arm } \\
\text { circumference }(\mathrm{mm})\end{array}$ & $+3 \cdot 7$ & $1.5(30)$ & $+7 \cdot 1$ & $1.5(30)$ & $+7 \cdot 8$ & $1 \cdot 6(27)$ \\
\hline
\end{tabular}

* For details of subjects and procedures, see pp. 602-604.

No significant differences were detected $(P<0.05)$ between any of the groups, by one-way ANOVA followed by the Scheffe test, for any of the indices listed in Table 3. 
Table 4. Changes in neuromuscular function scores in Gambian schoolchildren, aged 8-14 years, following supplementation with lactose (placebo), riboflavin, or a multinutrient supplement, for 6 weeks or 1 year*

(Mean values with their standard errors for $n$ subjects)

\begin{tabular}{|c|c|c|c|c|c|c|c|c|c|c|c|c|}
\hline & \multicolumn{6}{|c|}{ After 6 weeks' supplementation } & \multicolumn{6}{|c|}{ After 1 years' supplementation } \\
\hline & \multicolumn{2}{|c|}{$\begin{array}{l}\text { Group 1: } \\
\text { placebo } \\
(n 31)\end{array}$} & \multicolumn{2}{|c|}{$\begin{array}{l}\text { Group 2: } \\
\text { riboflavin } \\
(n 30)\end{array}$} & \multicolumn{2}{|c|}{$\begin{array}{l}\text { Group 3: } \\
\text { multinutrient } \\
\quad(n 27)\end{array}$} & \multicolumn{2}{|c|}{$\begin{array}{c}\text { Group 1: } \\
\text { placebo } \\
(n 31)\end{array}$} & \multicolumn{2}{|c|}{$\begin{array}{l}\text { Group 2: } \\
\text { riboflavin } \\
(n 30)\end{array}$} & \multicolumn{2}{|c|}{$\begin{array}{l}\text { Group 3: } \\
\text { multinutrient } \\
\quad(n \text { 27) }\end{array}$} \\
\hline & Mean & $\mathrm{SE}$ & Mean & $\mathrm{SE}$ & Mean & SE & Mean & SE & Mean & $\mathrm{SE}$ & Mean & $\mathrm{SE}$ \\
\hline $\begin{array}{r}\text { Test } 1 \\
\text { (sma } \\
\text { Test } 1\end{array}$ & +6.9 & $13 \cdot 5$ & $-28 \cdot 2$ & $17 \cdot 7$ & $-1 \cdot 8$ & $13 \cdot 0$ & $-47 \cdot 6$ & $12 \cdot 9$ & $-54 \cdot 6$ & $13 \cdot 1$ & $-29 \cdot 5$ & $13 \cdot 8$ \\
\hline hole, tremor) & $+29 \cdot 7$ & $9 \cdot 8$ & $+10 \cdot 4$ & $13 \cdot 7$ & $-2 \cdot 5$ & $8 \cdot 8$ & $-10 \cdot 2$ & $8 \cdot 0$ & $-6 \cdot 3$ & $8 \cdot 1$ & $-1 \cdot 2$ & 8.5 \\
\hline along wire) & $+22 \cdot 8$ & $14 \cdot 8$ & $+9 \cdot 5$ & $22 \cdot 2$ & +10.5 & $17 \cdot 9$ & $-30 \cdot 1$ & $19 \cdot 1$ & $-24 \cdot 8$ & $19 \cdot 4$ & -17.9 & $20 \cdot 4$ \\
\hline : aiming) & $+5 \cdot 5$ & $2 \cdot 2$ & +60 & $2 \cdot 0$ & $+4 \cdot 7$ & $1 \cdot 5$ & $+4 \cdot 2$ & $2 \cdot 1$ & $+6 \cdot 0$ & $2 \cdot 1$ & $+8 \cdot 7$ & $2 \cdot 2$ \\
\hline (pins, manipulation) & $+3 \cdot 2$ & $1 \cdot 0$ & $+3 \cdot 3$ & $1 \cdot 9$ & $+5 \cdot 1$ & $1 \cdot 3$ & $+4 \cdot 8$ & $1 \cdot 7$ & $+4 \cdot 4$ & 1.7 & $+9 \cdot 8$ & $1 \cdot 8$ \\
\hline
\end{tabular}

* For details of subjects and procedures, see pp. 602-603.

$\uparrow$ Values are mean changes in the number of contacts recorded during the specified measurement time for each test.

$\ddagger$ Values are mean changes in the number of pins placed correctly during the interval allowed.

No significant differences were detected $(P<0.05)$ between any of the groups, by one-way ANOVA followed by the Scheffé test, for any of the indices listed in Table 4.

\section{DISCUSSION}

It is clear, in view of the biochemical index values recorded in Table 1, that the Gambian schoolchildren who were selected for the present study were universally and severely deficient in riboflavin; moreover, the riboflavin supplementation schedule clearly resulted in a major improvement in riboflavin status, as measured biochemically. Before supplementation, $97 \%$ of the subjects were biochemically deficient, with EGRAC index values above $1 \cdot 4$, but during supplementation this percentage fell to $0 \%$ in group 2 (receiving the $25 \mathrm{mg}$ additional riboflavin/week), and to $79 \%$ in group 3 (receiving only $5 \mathrm{mg}$ additional riboflavin/week).

For ascorbic acid, $35 \%$ were biochemically deficient $(<11 \mu \mathrm{M}$-ascorbate in plasma) at the outset; this fell to $0 \%$ after 6 weeks in group 3 (receiving an extra $200 \mathrm{mg} /$ week) whereas it increased to $48 \%$ in groups 1 and 2 (receiving no additional ascorbic acid).

For folate, cobalamins and thiamin the proportion of biochemically deficient values at the outset was much smaller, and for vitamin $\mathbf{B}_{6}$ the limits of normality are less welldefined. Of these three biochemical indices only pyridoxal phosphate exhibited some improvement, attributable to the supplement in group 3. It should be noted that the erythrocyte samples for ETKAC measurements had been stored frozen for several weeks before the assay could be performed, which may have resulted in some losses of the coenzyme-depleted apoenzyme of transketolase, by degradation to non-reactivatable products (Puxty et al. 1985). For erythrocyte folate, the relatively small daily supplement $(107 \mu \mathrm{g})$ and the slow turnover rate of erythrocytes (4 months lifespan) may well account for the lack of a significant response in index levels in group 3, and for cobalamins it is likely 


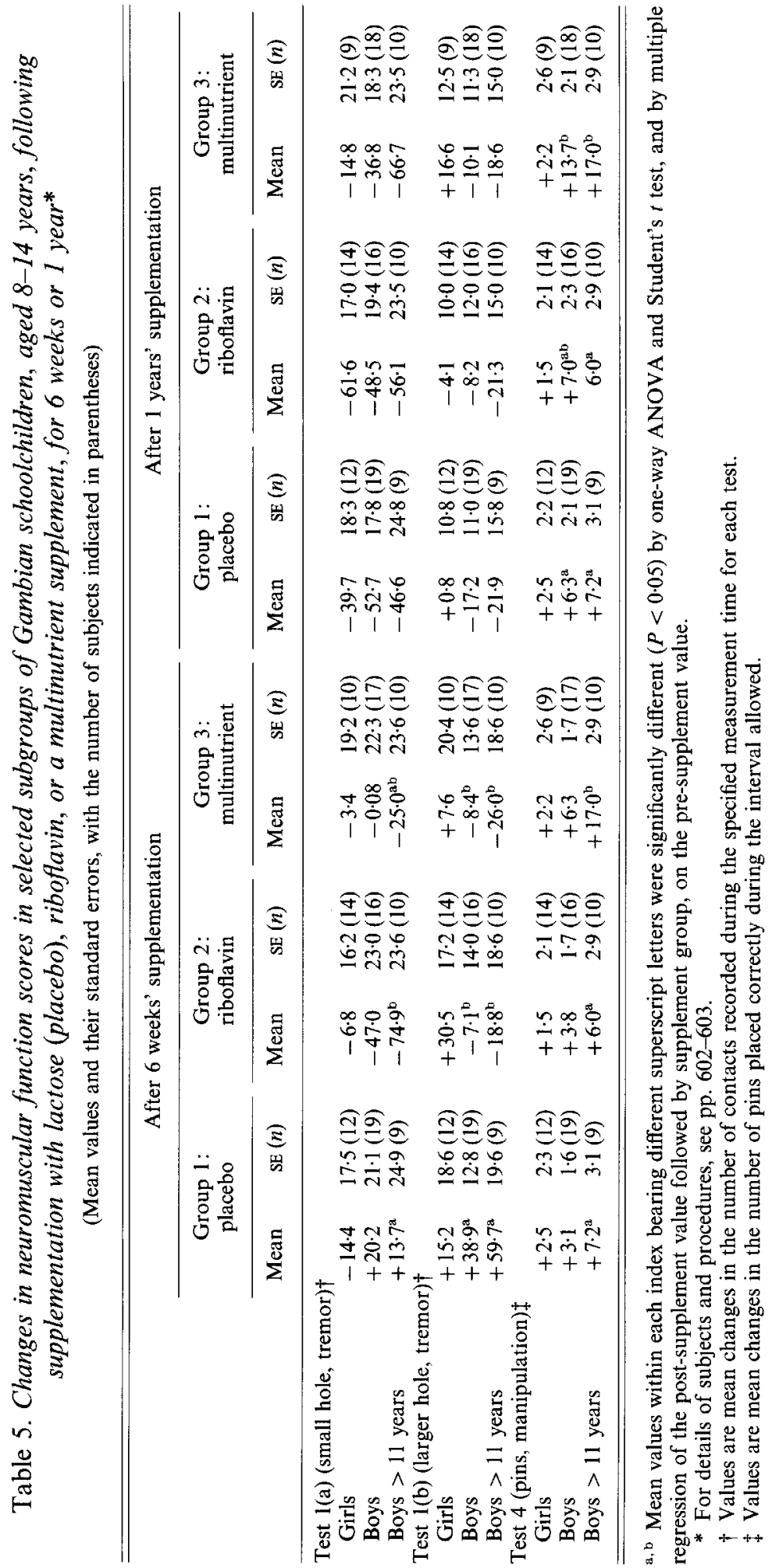


that most subjects were already adequately supplied from microbial sources, despite their mainly vegetarian diet.

The anthropometric and haematological indices did not benefit significantly from the supplements, and plasma ferritin exhibited only a small increase. In the case of the anthropometric indices this was not unexpected, because vitamin and $\mathrm{Fe}$ deficiencies may not be rate-limiting for growth in these children. Although $\mathrm{Fe}$ and riboflavin supplements can enhance haematological status indices in certain groups of this population (Powers et al. 1983; Powers \& Bates, 1987), this effect has proved variable between studies (Powers et al. 1985, 1987; Powers \& Bates, 1987; Bates et al. 1989). The occurrence of significant benefits may depend on the time of year and on the selection of haematologically high-risk subgroups. It may also vary from year to year, particularly with the severity of malarial or other diseases in the community.

Among the neuromuscular and other physiological indices, one significant change which seemed unequivocally attributable to the supplement was that of the probe tremor test in the boys after 6 weeks supplementation. The supplement-related response in the manipulation (pins) test at 1 year in the boys was also significant and in the expected direction. Preselection for relatively poor initial performance of these tasks may have helped to increase the supplement-effect. On the other hand, the neuromuscular tests depend upon the cooperation and comprehension of the subject, and on the skill of the invigilator in explaining and demonstrating the procedure. Whilst these factors were carefully controlled between subjects in the present study, it is doubtful whether precise matching of procedural details between studies is easily achievable. A more striking neuromuscular response to riboflavin supplementation might have been achieved if the test conditions had been optimized. Previous reports by Bamji et al. (1979) and Prasad et al. (1990) that Indian children exhibit similar responses to riboflavin or multinutrient supplements in the probe tremor test helps to enhance our belief that the response seen in the present study was not simply a procedural or a statistical artifact, e.g. of multiple testing. Nevertheless, further confirmation of these initially-promising observations is required, and their potential usefulness as practical indices of functional status needs to be verified.

With more sophisticated and discriminatory testing procedures, this work could usefully be extended and the mechanism of functional changes caused by subclinical micronutrient deficiencies could thus be explored.

We are indebted to the subjects for their cooperation; to the fieldworkers, particularly $\mathrm{Mr}$ B. Kanteh, for technical assistance; to Miss V. Christenssen for assistance with the biochemical assays; to the headmasters and staff of the English and Arabic schools in Keneba and the English school in Jali for their cooperation; and to F. Hoffmann-la-Roche, Basle, Switzerland for a generous gift of Protovit tablets. We thank Dr Anne Dale for onsite help with supervision and coordination, and Dr T. J. Cole for his statistical advice and assistance.

\section{REFERENCES}

Anastasi, A. (1976). Psychological Testing, pp. 445-467. New York: MacMillan.

Anderson, M. G. \& Kelly, A. M. (1981). Serum ferritin by a rapid and inexpensive ELISA method. Clinica Chimica Acta 116, 405-408.

Bamji, M. S., Arya, S., Rameshwar Sarma, K. V. \& Radhaiah, G. (1982). Impact of long-term, low dose Bcomplex vitamin supplements on vitamin status and psychomotor performance of rural school boys. Nutrition Research 2, 147-153.

Bamji, M. S., Rameshwar Sarma, K. V. \& Radhaiah, G. (1979). Relationship between biochemical and clinical indices of B-vitamin deficiency. A study in rural school boys. British Journal of Nutrition 41, 431-441.

Bates, E. J., Evans, P. H. \& Allison, G. $(1993 b)$. Responses to riboflavin and multinutrient supplements by Gambian school children. Proceedings of the Nutrition Society 52, 331A. 
Bates, C. J., Evans, P. H., Dardenne, M., Prentice, A., Lunn, P. G., Northrop-Clewes, C. A., Hoare, S., Cole, T. J., Horan, S. J., Longman, S. C., Stirling, D. \& Aggett, P. J. (1993a). A trial of zinc supplementation in young rural Gambian children. British Journal of Nutrition 69, 243255.

Bates, C. J. \& Powers, H. J. (1989). Studies on micronutrient intakes and requirements in The Gambia. Journal of Human Nutrition and Dietetics 2, 117-124.

Bates, C. J., Powers, H. J. \& Thurnham, D. I. (1989). Vitamins, iron and physical work. Lancet 2, 313-314.

Bates, C. J., Prentice, A. M., Prentice, A., Paul, A. A. \& Whitehead, R. G. (1982a). Seasonal variations in ascorbic acid status and breastmilk ascorbic acid levels in rural Gambian women with relation to dietary intake. Transactions of the Royal Society of Tropical Medicine and Hygiene 76, 341-347.

Bates, C. J., Prentice, A. M., Prentice, A., Sharkey, K. A., Murphy, P. K. \& Villard, L. (1982 b). Physiological tests during an improvement in riboflavin status in lactating Gambian women. International Journal of Vitamin and Nutrition Research 52, 14-23.

Benton, D. (1992). Vitamin-mineral supplements and intelligence. Proceedings of the Nutrition Society 51, $295-302$

Camp, V. M., Chipponi, J. \& Faraj, B. A. (1983). Radioenzymatic assay for direct measurement of plasma pyridoxal 5-phosphate. Clinical Chemistry 29, 642-644.

Dacie, J. V. \& Lewis, S. M. (1975). Practical Haematology 5th ed. Edinburgh: Churchill Livingstone.

Fuller, N. J., Bates, C. J., Hayes, R. J., Bradley, A. K., Greenwood, A. M., Tulloch, S. \& Greenwood, B. M. (1988). The effects of antimalarials and folate supplements on haematological indices and red cell folate levels in Gambian children. Annals of Tropical Paediatrics 8, 61-67.

Haralambie, G. (1976). Vitamin $B_{2}$ status in athletes and the influence of riboflavin administration on neuromuscular irritability. Nutrition and Metabolism 20, 1-8.

Machlin, L. J. (ed.) (1984). Handbook of Vitamins. Nutritional, Biochemical and Clinical Aspects, pp. 225, 284, 317, 483. New York and Basel: Marcel Dekker Inc.

Nathanail, L. \& Powers, H. J. (1992). Vitamin A status of young Gambian children: biochemical evaluation and conjunctival impression cytology. Annals of Tropical Paediatrics 12, 67-73.

Powers, H. J. \& Bates, C. J. (1987). Micronutrient deficiencies in the aetiology of anaemia in a rural area in The Gambia. Transactions of the Royal Society of Tropical Medicine and Hygiene 81, 421-425.

Powers, H. J., Bates, C. J., Eccles, M., Brown, H. \& George, E. (1987). Bicycling performance in Gambian children : effects of supplements of riboflavin or ascorbic acid. Human Nutrition: Clinical Nutrition 41, 59-69.

Powers, H. J., Bates, C. J., Lamb, W. H., Singh, J., Gelman, W. \& Webb, E. (1985). Effects of multivitamin and iron supplements on running performance in Gambian children. Human Nutrition: Clinical Nutrition 39C, $427-437$

Powers, H. J., Bates, C. J., Prentice, A. M., Lamb, W. H., Jepson, M. \& Bowman, H. (1983). The relative effectiveness of iron, and iron with riboflavin, in correcting a microcytic anaemia in men and children in rural Gambia. Human Nutrition: Clinical Nutrition 37C, 413-425.

Powers, H. J., Weaver, L. T., Austin, S. \& Beresford, J. K. (1993). A proposed intestinal mechanism for the effect of riboflavin deficiency on iron loss in the rat. British Journal of Nutrition 69, 553-561.

Prasad, P. A., Bamji, M. S., Lakshmi, A. V. \& Satyanarayana, K. (1990). Functional impact of riboflavin supplementation in urban school children. Nutrition Research 10, 275-281.

Prentice, A. M., Lamb, W. H. \& Bates, C. J. (1983). A trial of ascorbic acid and of multivitamin supplementation on the oral health of West African children. Transactions of the Royal Society of Tropical Medicine and Hygiene 77, 792-795.

Puxty, J. A. H., Haskew, A. E., Ratcliffe, J. G. \& McMurray, J. (1985). Changes in erythrocyte transketolase activity and the thiamine pyrophosphate effect during storage of blood. Annals of Clinical Biochemistry 22 , $423-427$

Shin-Buehring, Y. S., Rasshofer, R. \& Endres, W. (1981). A new enzymatic method for pyridoxal-5-phosphate determination. Journal of Inherited Metabolic Disease 4, 123-124.

Sterner, R. T. \& Price, W. R. (1973). Restricted riboflavin: within subject behavioural effects in humans. American Journal of Clinical Nutrition 26, 150-160.

Tanner, J. M., Whitehouse, R. H. \& Takaishi, M. (1966). Standards from birth to maturity for height, weight, height velocity and weight velocity: British children, 1965 part II. Archives of Disease in Childhood 41, 613-635.

Vuilleumier, J. P. \& Keck, E. (1989). Fluorometric assay of vitamin C in biological samples using a centrifugal analyser with fluorescence attachment. Journal of Micronutrient Analysis 5, 25-34.

Vuilleumier, J. P., Keller, H. E. \& Keck, E. (1990). Clinical chemical methods for the routine assessment of the vitamin status in human populations part III. The apoenzyme stimulation tests for vitamin $B_{1}, B_{2}$ and $B_{6}$ adapted to the Cobas-Bio analyser. International Journal of Vitamin and Nutrition Research 60, $126-135$. 